\title{
HAEMODIALYSIS IN B. P. KOIRALA INSTITUTE OF HEALTH SCIENCES, DHARAN - AN INITIAL EXPERIENCE
}

\section{ABS TRACT}

Sharma $S K^{1}$, Kumar $\mathrm{P}^{2}$, Chapagain $\mathrm{A}^{3}$, Koirala $\mathrm{S}^{4}$

Dialysis supports life, in spite of complete cessation of renal functions. Haemodialysis $(\mathrm{HD})$ service became available in B. P. Koirala Institute of Health Sciences, Dharan since September 1999. Six hundred and sixty one sessions of $H D$ in 50 patients were carried out in one year. End stage renal disease (ESRD), acute renal failure (ARF), acute on chronic renal failure constituted 54\%, $26 \%$ and $20 \%$ of the patients respectively. Majority of the patients (72\%) were between 15 to 50 years of age. Chronic glomerulonephritis, chronic interstitial nephritis, and diabetes nephropathy were the most common causes of ESRD. Recovery following $\mathrm{HD}$ was $70 \%$ in ARF, while all patients of acte on chronic renal failure improved following few sessions of HD. Drop out rate on maintained haemodialysis (MHD) was 52\%. The increasing demand of dialysis service in this region is diffialt to fulfill de to restricted facilities for dialysis, ladk of renal transplantation in Nepal, and economic constraint in the partof patients. Primary and secondary prevention of renal diseases by community education, awareness and participation needs emphasis.

Key Words: Haemodialysis, End stage renal disease, Aate renal failure, Acute on chronic renal failure.

\footnotetext{
1. Assistant Professor, Department of Medcinie, B.P. Koirala Institute of Health Sciences, Dharan, Nepal.

2. Senior Resident, Department of Medicine, B.P. Koirala Institute of Health Sciences, Dharan, Nepal.

3. House Of ficer, Department of Medicine, B.P. Koirala Institute of Health Sciences, Dharan, Nepal.

4. Professor, Department of Medicine, B.P. Koirala Institute of Health Sciences, Dharan, Nepal.

Address for correspondence : Dr. Sanjib Kumar Sharma, MD., Department of Medicine

B.P. Korala Institute of Health Sciences, Dharan, Nepal.

E-mail: drsanjib@yahoo.com, Fax: 00977-25-20251
} 
INTRODUCTION

The modem era of haemodialysis (HD) introduced by Kolf and Murray in early 1940's now constitutes the most cormon form of renal replacement therapy worldwide. ${ }^{1}$ In Nepal, $H D$ was started initially on $5^{\text {th }}$ October 1988 in Bir Hospital, Kathmandu. ${ }^{2}$ Since then HD service became available in various centres in Kathmandu. However, to find its place atside the capital city it took another decade. Dialysis division was started under department of medicine at B. P Koirala Institute of health Sciences Dharan in $9^{\text {th }}$ September 1999. Six hundred sixty one sessions of HD were carried at dring one year period in fifty patients. In this prospective study the relevant data are analysed.

M ATERIAL AND METHODS

Fifty patients managed by HD from September 1999 to August 2000 composed of ESRD (End stage renal disease). Aate on chronic renal failure and acute renal failure (ARE). The pre-designed haemodialysis record sheet, case sumary and dialyser re-use records were maintained and analysed. ARF, ESRD and chronic renal failure (CRE) were diagnosed on the basis of biochemical, radiological and clinical findings. In case of maintenance haemodialysis (MHD), adequacy of dialysis was assessed by Kt/ V, based on the formula proposed by Jindal et al. ${ }^{3}$

\section{RES ULTS}

Total of 661 sessions of $\mathrm{HD}$ has been carried out in 50 patients of renal failure patients requiring dialysis therapy. Majority (72\%) of the patients were below 50 years of age (Table: 1 )
Table: 1 Age distribution of patients on $\mathrm{HD}$

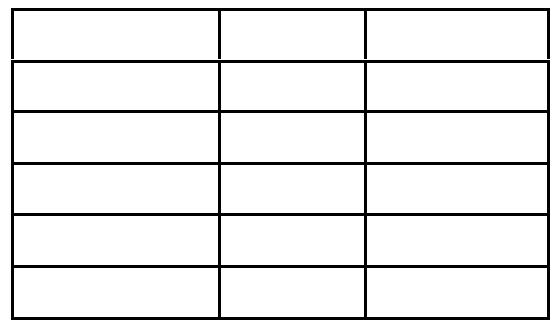

Nine HD sessions were carried out in the fist month of initiation of $\mathrm{HD}$. After one year it has shamply increased and 88 sessions of $\mathrm{HD}$ were done in the month of August 2000. (Fig: 1). RSRD, ARF and

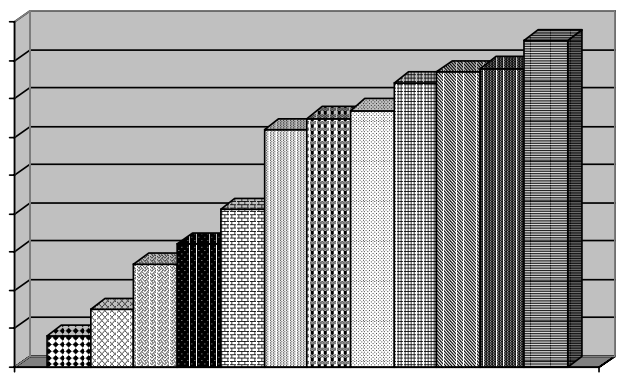

\begin{tabular}{|c|c|c|c|c|c|}
\hline 国 & 圆 & 图 & $\square$ & 圖 & 圈 \\
\hline 두 & 圆 & 团 & $\mathbb{\Delta}$ & 四 & 目 \\
\hline
\end{tabular}

acute on $\mathrm{CRF}$ were present in 27 (54\%), 13 (26\%) and 10 (20\%) of the patients respectively (Table:2)

Table: 2 Diagnosis at the time of first $H D$

\begin{tabular}{|l|l|l|}
\hline & & \\
\hline & & \\
\hline & & \\
\hline & & \\
\hline
\end{tabular}

The common causes of ESRD were chronic glomenulonephritis (COV) and chronic interstitial nephritis (CIN). They constitute 55.5\% $(n=15)$ of cases. Diabetic nephropathy was placed third $(30 \%)$. Costructive uropathy and renal transplant rejection constituted the rest (14.5\%). Post gastroenteritis $(n=4)$ and road traf fic accident $(n=4)$ were found to be common causes of ARF in patients 
undergoing $\mathrm{HD}$. The cormon indications for undertaking $H D$ were shown in table 3. Most of the patients had two or more indications for dialysis. 30 patients had metabolic acidbsis and it was the cormonest indication for $\mathrm{HD}$.

Table: 3 Indications of dialysis

\begin{tabular}{|l|l|}
\hline & \\
\hline & \\
\hline & \\
\hline & \\
\hline & \\
\hline & \\
\hline
\end{tabular}

The majority (70\%) of ARF patients recovered, whereas all patients of acute on CRF had improved after, on an average, five sessions of $\mathrm{HD}$. Mbst of the patients $(n=14)$ of ESRD dropped out after initial session of $\mathrm{HD}$ (Table: 4). Among the drop outs most of the patients ( (52\%)) had undergone maximm of five sessions of dialvsis.

Table: 4 Outcome of patients on $\mathrm{HD}$

\begin{tabular}{|l|l|l|l|l|}
\hline & & & & \\
\hline & & & & \\
\hline & & & & \\
\hline & & & & \\
\hline
\end{tabular}

Patients who were on $M \mathrm{D}$, in seven patients, kt/ $\mathrm{V}$ was more than 1 (1 to 1.5) while 3 patients had $\mathrm{kt} / \mathrm{v}$ below 1 signifying inadequacy of $\mathrm{HD}$ treatment. Almost all patients had inter-aurrent ailment while on MD. Four patients were infected with tuberculosis, two developed respiratory tract infections, whereas infective endocarditis, disseminated herpes zoster and gangrenous change of a-v fistula ocourred in one each.

\section{DISCUSSION}

Haemodialysis has proven as a viable renal replacement therapy (RRT) for last four decades. The demographic profile of patients undergoing
HD varies in different countries and is influenced by rates of renal transplantation and restricted facilities for dialysis. However, the major determinant of RRT is certainly economic. The acceptance for RRT is low in developing countries for various reasons. In Bangladesh only $2 \%$ of the ESRD patients are accepted for dialysis and transplantation. ${ }^{5}$ Such data are not available from Nepal.

The majority of our patients are in the age group of 15 to 50 years. The involvement of age group in the present study corrdborates with another report from Nepal and also with that from India. ${ }^{2,6}$ The median age of patients with ESRD in USA is 60 years, according to data from U.S. Renal Data System (USRDS). The affliction of younger age group in the most productive age group in developing countries has wide socio-economic implications. The common precipitating cause of $\mathrm{CRF}$ was uncontrolled hypertension $(\mathrm{n}=4)$ followed by infection $(n=3)$. Majority of the patients undergoing $H D$ were suffering from ESRD. Most of the patients with $A R F$ underwent peritoneal dialysis due to constraint in $\mathrm{HD}$ machine in our center.

The most common cause of ESRD was CGN and CIN (55.5\%). These two diseases are often dif fiaitt todif ferentiate as patients presented to us at ESRD, though absence of severe hypertension, adequate urine output and absence of edema may point towards CIN. Diabetes (30\%) as a cause of ESRD was placed second in this series. In USA diabetic nephropathy is the most cormon (32\%) cause of ESRD, followed by hypertensive nephrosclerosis (28\%) and CGN (15\%), While in Europe CGN (24\%), CIN (17\%) and diabetic nephropathy (12\%) are three major causes of ESRD. ${ }^{8}$ In the study from Chandigarh ${ }^{9}$ CGN stood as the commonest cause of ESRD (37\%) and was followed by diabetic nephropathy (24\%) and hypertension (13\%) . 
Almost all patients with ESRD presented to us with life threatening complications like metabolic acidosis, pulmonary edema, encephalopathy, hyperkalemia and pericarditis in various combinations for which HD was undertaken. In $C R F$, it is recommended that elective dialysis should be started when creatinine clearance falls below $10 \mathrm{ml} / \mathrm{min} / 1.73$ Square Meter of body surface area. ${ }^{10}$ The recommendation is hardly applicable to our patients as they presented late probably due to lack of awareness of renal diseases. In adbition, economic constraints prevented them from utilising the available treatment.

During the one-year period a total of 50 patients had undergone $\mathrm{HD}$. Two patients died from primary illness. Majority (52\%) of the patients dropped out after initial 5 or less sessions of dialysis. The drop at rates in series by Subedi et al and chetri et al were $28 \%$ and $35.7 \%$ respectively. ${ }^{2,11}$ In spite of the fact that the survival rate of patients with ESRD without RRT is poor, patients were unable to continue $\mathrm{MHD}$, probably due to financial constraints and non-availability of space for MD. Ladk of renal transplant facility in our country and lack of renal donor may be two other important factors.

Complication during haemodialysis is common. Acute complications like hypotension, muscle cramp, nausea, vomiting, headache, chest pain were routinely encountered. Infections in the dialysis patients constitute a major cause of morbidity due to multiple defects in host resistance. ${ }^{12}$ In our small series tuberaulosis was detected in 5 patients. The incidence of tuberaulosis has been estimated to be tenfold higher among $\mathrm{HD}$ patients than general populations. ${ }^{13}$ The quality of life and adequacy of dialysis is similar factor that needs close analysis in patients who are undergoing MD. In this preliminary analysis it was found that $\mathrm{Kt} / \mathrm{v}$ was more than 1 in 70\% of the patients.
Analysis from randomised National Co-operative Dialysis Study (NCDS), it was found that if $\mathrm{Kt} / \mathrm{v}$ is $<0.8$, there is higher rate of mortality and morbidity. Reanalysis of NODS by Hakim et. al. ${ }^{15}$ concluded that higher the Kt/v above unity, better is the outcome. Therefore, it is mandatory to keep close doservation on adequacy of dialysis in patients who are undergoing MHD.

\section{CONCLUSION}

The number of patients requiring dialysis is expected to increase in future in BPKIHS, which caters entire Fastem Nepal and bordering districts of India. This increase in demand is certainly dif fialt to cope de to limitations related to various resources like manpower, machinery and investment. Availability of renal transplant facility in the country, more dialysis units with adequate resarces and social insuring may partially fulfill the demand. The efforts must be combined with prevention of renal disease by health education, comminity awareness, early detection and ef fective control of primary and secondary renal diseases to reduce the burden of ESRD.

\section{REFERENCE}

1. Steven J. Peitzman. Origins and early reception of clinical dialysis. Am J Nephrol 1997; 17: 299303 .

2. Subedi B K, Kafle R K, Satyal P R, Haemodialysis in Nepal. A review. J. Inst. Med. 1991; 13: 133138 .

3. Jindal K K, Manual A, Goldstein M B, Percent reduction in blood urea concentration during haemodialysis (PRU). A simple and accurate method to estimate kt/v urea. Trans Am Soc Artif Inter Organs 1987; 33: 286-288.

4. Lowrie EG. Chronic dialysis treatment. Am J Kidney Dis. 1994; 24: 255-266 
5. Rashid H U, Rahman H, Nephrology services in Bangladesh - A neglected field in Medicine. Bangladesh Renal J 1986; 51:3-4.

6. Sakuja V, Jha V, Ghosh A K, Ahmed S, Shahu T K, Chronic renal failure in India. Nephrol Dial Transplant 1994: 9: $871-872$.

7. U. S. Renal Data System, USRDS 1990 Annual data report. Causes of ESRD. Am J. Kidney Dis. 1990; suppl-2: 220.

8. Wing A J, Brenner F P, Twenty three years of dialysis and transplantation in Europe: Experience of the EDTA registry. Am J Kidney Dis 1989; 16: $341-347$.

9. Mani MK, Chronic renal failure in India. Nephrol Dial Transplant 1993; 8: $684-689$.

10. Edward T, Zawada Jr. Indications of dialysis. In: handbook of Dialysis. J T Daugirdas, T S Ing, eds. Boston, little, Brown and Company, p. 3, 1994.
11. Chhetri P K, Satyal P R, Kafle R, Khakhurel S, Pradhan B R, Experience of haemodialysis in Bir Hospital. Nepal Med. Col. J 1999; 2: 99- 100.

12. Goldblum R E, Reed W P, Host defense and immunologic alteration associated with chronic haemodialysis. Ann Intern Med. 1980; 93: 597613.

13. Joseph R, Lentino, David J. Leehay. infections. In: handbook of Dialysis. J. T. Daugirdas, T. S. Ing, eds. Boston, little, Brown and Company, p.473, 1994.

14. Gotch F A, Sergean J A. A mechanistic analysis of national co-operative dialysis study (NCDS) . Kidney Int. 1985; 28: $526-534$.

15. Hakim R M, Depner T A, Parker T P Adequacy of Haemodialysis. Am J. Kidney Dis 1992:20: 107123.

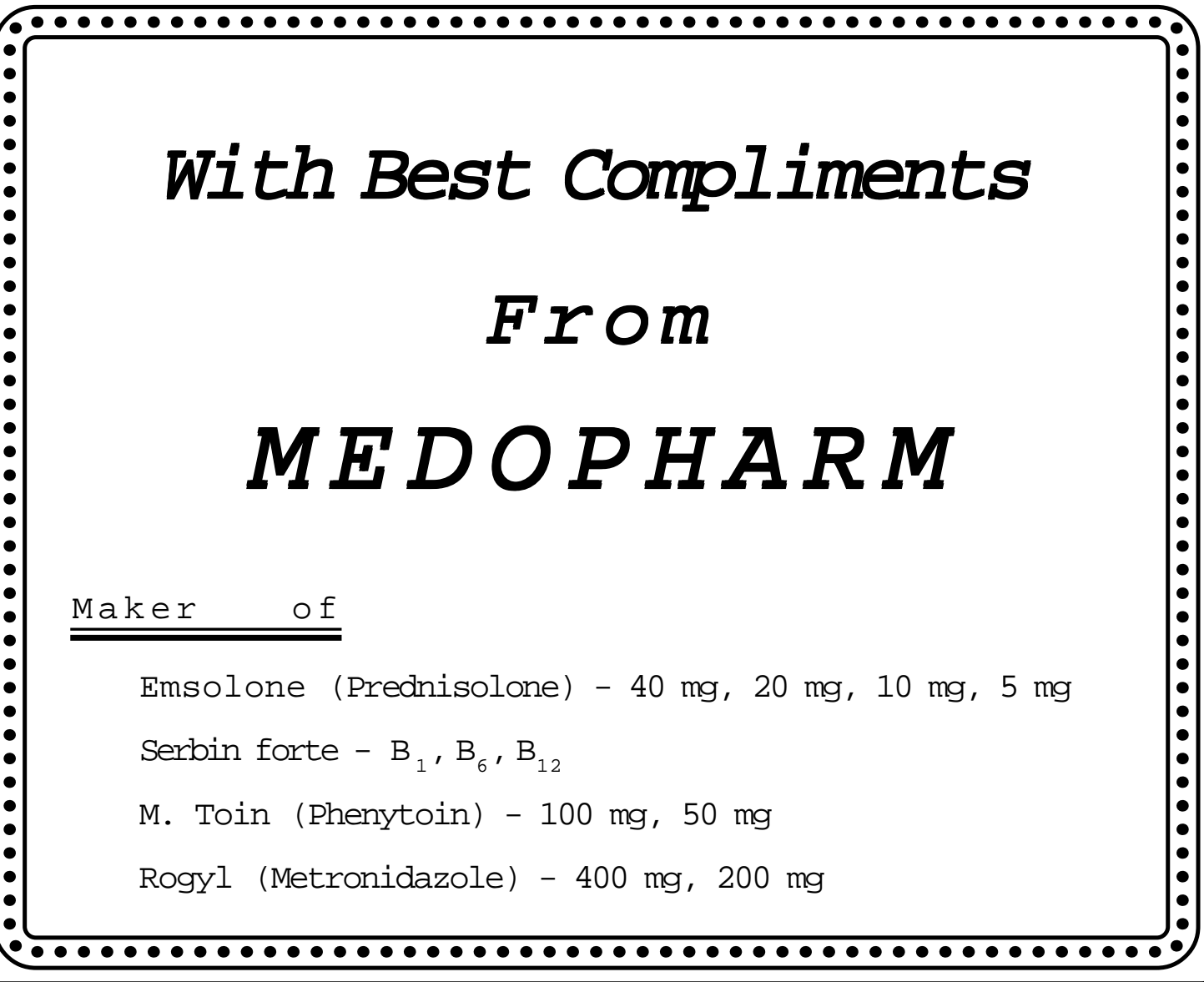

JNMA, July - September, 2001, 40 